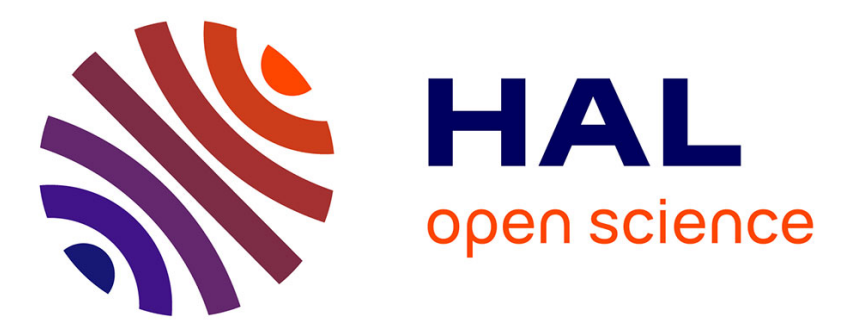

\title{
Temperature variation in the workpiece and in the cutting tool when dry milling Inconel 718
}

\author{
Gael Le Coz, D. Dudzinski
}

\section{To cite this version:}

Gael Le Coz, D. Dudzinski. Temperature variation in the workpiece and in the cutting tool when dry milling Inconel 718. International Journal of Advanced Manufacturing Technology, 2014, 74 (5-8), pp.1133-1139. 10.1007/s00170-014-6006-1 . hal-03040844

\section{HAL Id: hal-03040844 \\ https://hal.univ-lorraine.fr/hal-03040844}

Submitted on 4 Dec 2020

HAL is a multi-disciplinary open access archive for the deposit and dissemination of scientific research documents, whether they are published or not. The documents may come from teaching and research institutions in France or abroad, or from public or private research centers.
L'archive ouverte pluridisciplinaire HAL, est destinée au dépôt et à la diffusion de documents scientifiques de niveau recherche, publiés ou non, émanant des établissements d'enseignement et de recherche français ou étrangers, des laboratoires publics ou privés. 


\title{
Temperature variation in the workpiece and in the cutting tool when dry milling Inconel 718
}

\author{
G. Le Coz, D. Dudzinski \\ Laboratoire d'Etude des Microstructures et de Mécanique des Matériaux \\ (LEM3), UMR CNRS 7239, Université de Lorraine4, Rue Augustin Fresnel, \\ 57070 Metz, France \\ Corresponding author. E-mail address : daniel.dudzinski@univ-lorraine.fr
}

\begin{abstract}
When dry machining of difficult to cut materials, the cutting temperature is an important parameter for the optimization of cutting conditions. However, this one must be measured as close as possible to the cutting area; in addition, it is also essential to know the temperature gradients. A moderate level of cutting edge temperature and a low thermal shock reduce the tool wear phenomena; and, a low temperature gradient in the machined sublayer reduces the risk of high tensile residual stresses.

This paper deals with temperature and temperature gradient measurements during dry peripheral milling of Inconel 718. The thermocouple method was used to measure the temperature of the machined surface and in the subsurface layer. An original thermocouple was specially developed for measuring the temperature surface. The measurements were used to determine the temperature gradients and to reconstruct the thermal heating of the cutting edge at every tool revolution, and for different cutting speed values.
\end{abstract}

\section{Mots clés.}

milling, Inconel 718, temperature, gradient, measurement, interrupted cutting 


\section{INTRODUCTION.}

Inconel 718 is a Nickel based superalloy widely employed in aeronautical, aerospace and energy industries for parts undergoing high mechanical loads under high operating temperature, due to their high temperature strength and high corrosion resistance. Due to its high temperature properties, its poor conductibility, its elevated strain hardening and strain rate sensitivity, Inconel 718 is among the most difficult-to-cut materials. The difficulty of machining results in short tool life and poor surface integrity. The heat generation and the plastic deformation induced during machining affect the machined surface. In particular, he heat generated alters the microstructure of the alloy, induces residual stresses and activates the tool wear mechanisms. The low thermal conductivity of Inconel 718 leads to high cutting temperatures in the cutting zones.

Different studies have been conducted to determine cutting temperature when machining Inconel 718, particularly in turning. Great variations appear concerning the temperature values measured by the researchers, depending on cutting conditions but also on the experimental method. Using of a thermocouple method in which the thermocouple was composed of the work material and a tungsten wire buried in a ceramic tool, Narutaki et al. (1993) estimated the rake and the flank temperatures during turning tests. In the cutting speed range of $400-500 \mathrm{~m} / \mathrm{min}$, the flank temperature attained $1300{ }^{\circ} \mathrm{C}$. This high cutting temperature values were confirmed by El Wardany et al. (1996). They performed temperature measurements during turning operations, using a thermocouple inserted in the tool rake face as close as possible to the cutting edge. In addition, a finite element analysis was employed to predict the temperature distribution and the cutting tool edge temperature. For their experiments, Al203-TiC ceramic tools were used and high cutting speed and feed rate values were chosen; a maximum temperature of $1100^{\circ} \mathrm{C}$ was found. In the same way, Kitagawa et al. (1997) reported a tool temperature of $900^{\circ} \mathrm{C}$ at the low cutting speed of $30 \mathrm{~m} / \mathrm{min}$ and $1300 \circ \mathrm{C}$ at $300 \mathrm{~m} / \mathrm{min}$, during turning tests. These temperatures were measured by using a similar thermocouple method to that used by Narutaki et al. (1993). Coelho et al. (2004) measured rake face temperature during turning tests at high cutting speeds. They pointed out that thermal conductivity of tool material and coating may greatly modify the measured temperature. The temperature increase on the rake face, was found less than $100^{\circ} \mathrm{C}$ for ceramic tools and around $200-300^{\circ} \mathrm{C}$ for PCBN tools; however, the measurements were performed at $1.5 \mathrm{~mm}$ from the cutting edge. The maximum temperature was generated in the tool nose region, thus the temperature gradients in the tool were steep and the 
measured temperature value was less than the previous ones. Courbon et al. (2009) carried out Inconel 718 turning tests with PVD TiAIN-coated carbide tool at the recommended cutting speed of $50 \mathrm{~m} / \mathrm{min}$. Rake face temperature was measured with an embedded thermocouple near the rake face and the cutting edge. Depending on the lubrication conditions, they obtained a temperature between $130^{\circ} \mathrm{C}$ for high-pressure jet assistance and $400^{\circ} \mathrm{C}$ for dry cutting.

In milling, to measure the cutting temperature is more complex due to the process itself. The tool rotates at high speed, the cutting action is confined and the cutting tool is not in constant operation, undergoing a heat and cool cycle during the intermittent cutting (Lezanski and Shaw, 1990). The heat cycle is not measured by an embedded thermocouple on the tool (Le Coz et al., 2012) or by the observation of a near surface with an infrared pyrometer (Lin, 1995) (Ming et al., 2003) or a thermography camera (Pittala and Monno, 2011). Another regularly used method is the embedded thermocouple in the workpiece. Without measuring a heating cycle, $\mathrm{Ng}$ et al. (2000) estimated the temperature when ball-end milling Inconel 718 using a $\mathrm{K}$ type thermocouple with a measuring junction bead diameter of $0.3 \mathrm{~mm}$. The thermocouple was implanted in a microhole of $0.4 \mathrm{~mm}$, secured to and insulated to the workpiece by porcelain cement. Temperatures were measured under the surface and values between $330{ }^{\circ} \mathrm{C}$ and $420{ }^{\circ} \mathrm{C}$ were reported when dry milling at $90 \mathrm{~m} / \mathrm{min}$. The use of an optical fiber inserted in a fine hole from the outer surface and connected to an infrared pyrometer allowed to estimate the heating cycle of the flank face of a cutting tool when milling (Ueda et al., 2001). Other fibers were placed around the tool and measured temperature at various intervals after cutting, and the tool cooling cycle was thus evaluated. Recently, Sato et al. (2011) were able to evaluate the heating cycle of the tool rake face using pyrometer and optical fiber inserted on the rotating end mill.

Due to its low thermal diffusivity and its high strength properties, the cutting process of Inconel 718 alloy generates high temperature values localized in the cutting zone. Thus, a great temperature gradient may be observed from the new generated surface to the subsurface. The aim of this experimental work was to evaluate this temperature gradient in the workpiece and access to the cutting edge temperature when peripheral milling Inconel 718. Two experimental set ups were developed, based on the thermocouple method. The first device measured temperature on subsurface at $0.5 \mathrm{~mm}$ under the new generated surface. The temperature on the machined surface and probably on the tool cutting edge 
surface was determined with a second device. The influence of cutting speed on cutting and temperature gradient temperature was investigated.

\section{EXPERIMENTAL METHOD.}

\subsection{Experimental procedure.}

The experiments were carried out on a high speed machining center Roeders RP600. The workpieces were mounted a dynamometric table Kistler 9265B to measure the cutting forces during the processs. The workpiece material was a solution treated and aged Inconel 718 alloy, with hardness of $38 \mathrm{HRC}$, and the standard chemical composition ; 50-55\% Ni, 0.020.08\%C, 17-21\%Cr, 0.7-1.15\%Ti, 4.8-5.5\% Nb+Ta,0.3-0.7\%Al, 2.8-3.3\%Mo, 0.35max\%Si, 1\% max Co (Devillez and al., 2011). The material characteristics, at room temperature, are: a thermal conductivity $\mathrm{k}=11.4 \mathrm{~W} / \mathrm{m} . \mathrm{K}$, a density $\rho=9190 \mathrm{~kg} / \mathrm{m}^{3}$, and a heat capacity $\mathrm{c}=435$ $\mathrm{J} / \mathrm{kg}$.K. Samples were parallelepipeds of $50 \mathrm{~mm}$ length and $8 \mathrm{~mm}$ height specially prepared to integrate thermocouples. The width was initially of $75 \mathrm{~mm}$, it was reduced of radial depth of cut after each cutting test. Peripheral milling operations were performed on the height of the specimens.

A two teeth Sandvik R390 end mill of $16 \mathrm{~mm}$ diameter was used. The tool was a PVD TiAIN multilayer coated carbide insert (grade GC1030). This PVD coating carbide was developed for milling operations at medium speeds for refractory superalloys. A large interval of values for the cutting speed was chosen. Moderate values of 40,60 and $80 \mathrm{~m} / \mathrm{min}$ were first taken, they are usual values chosen for carbide tools. In addition, higher values of 160 and 320 $\mathrm{m} / \mathrm{min}$ were tested. Down milling operations were performed with a feed rate of 0.07 $\mathrm{mm} /$ tooth. The axial depth of cut was $8 \mathrm{~mm}$, and the radial depth of cut was equal to $1 \mathrm{~mm}$.

\subsection{Temperature measurement devices}

Cutting induced temperatures of workpiece were measured at various cutting conditions by using inserted thermocouples. Two different experimental setups were developed for these measurements.

For the first one, a commercial K-type thermocouple was implanted into the workpiece into a $0.5 \mathrm{~mm}$ diameter hole. The measuring junction was positioned precisely at $1.5 \mathrm{~mm}$ from the surface of the sample, see figure 1, and a conductor paste was injected over the junction in 
the through hole containing the thermocouple. During the milling tests, the radial depth of cut was of $1 \mathrm{~mm}$; thus, the measuring point was at $0.5 \mathrm{~mm}$ from the new generated surface.

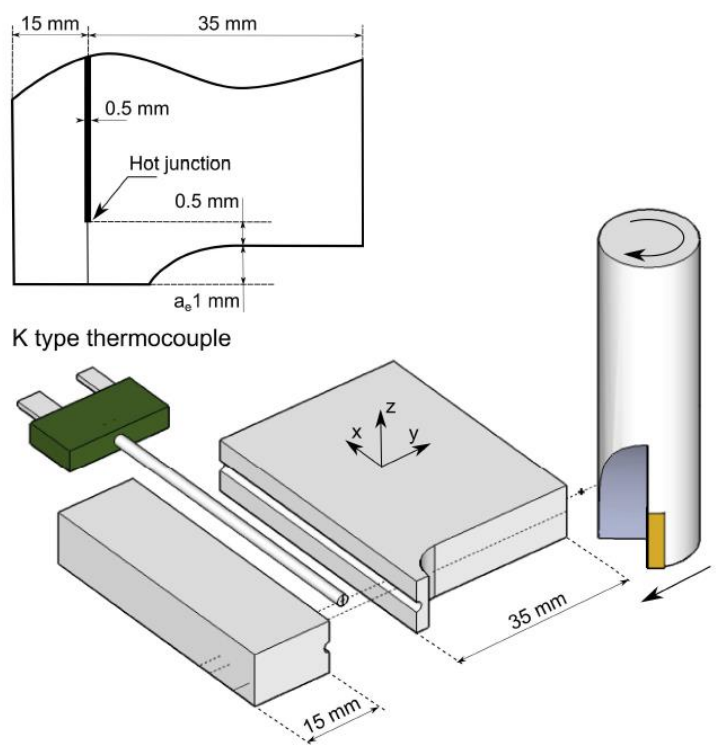

Fig.1. Schematic illustration of the subsurface measurement device

Typical signals of the normal force (along the $\mathrm{x}$-direction) and of the measured temperature during a milling test with a cutting speed of $80 \mathrm{~m} / \mathrm{min}$ are shown in Figure 2. The input of the tool in the workpiece is observed at time $t=1 \mathrm{~s}$ with the cutting force signal; then the thermocouple junction is then at room temperature. At time $t=8 \mathrm{~s}$, the temperature signal increases rapidly and reaches its maximum at time $t=12 \mathrm{~s}$, when the tool is in front of the thermocouple. It may be noted that a slight decrease in the cutting force is observed when the tool is crossing the micro-hole. After this temperature peak, the measured temperature gradually decreases and tends to the ambient temperature, which was reached after stopping the machining.

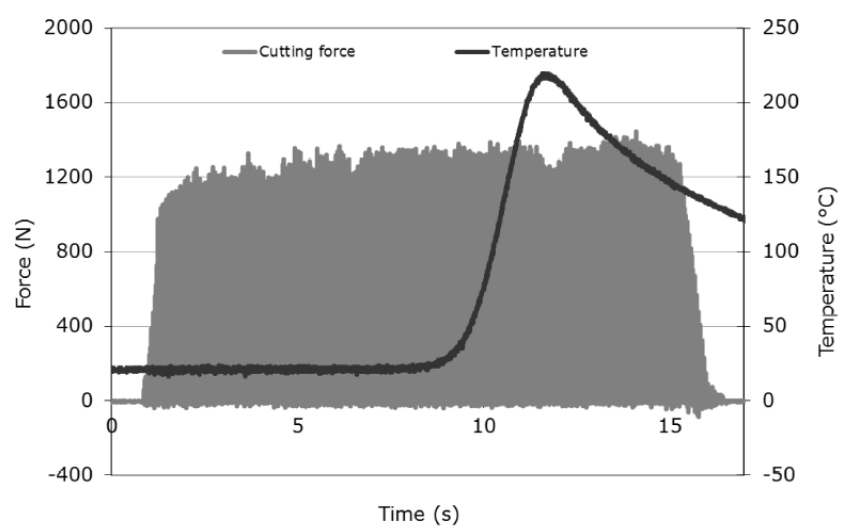

Fig.2. Typical force and temperature signals for a cutting speed of $80 \mathrm{~m} / \mathrm{min}$ 
A specially developed machinable thermocouple was used for the second setup, Figure 3, where the hot junction is realized by the passage of the cutting edge. It consists of two dissimilar conductors, iron and constantan, to form a standardized J-type thermocouple combination insulated by using mica. The test specimens were made of two parts, the thermocouple was inserted and pressed between the two parts of the specimen and all along a groove $(0.6 \mathrm{~mm} \times 2 \mathrm{~mm})$ performed in the one of the two parts.

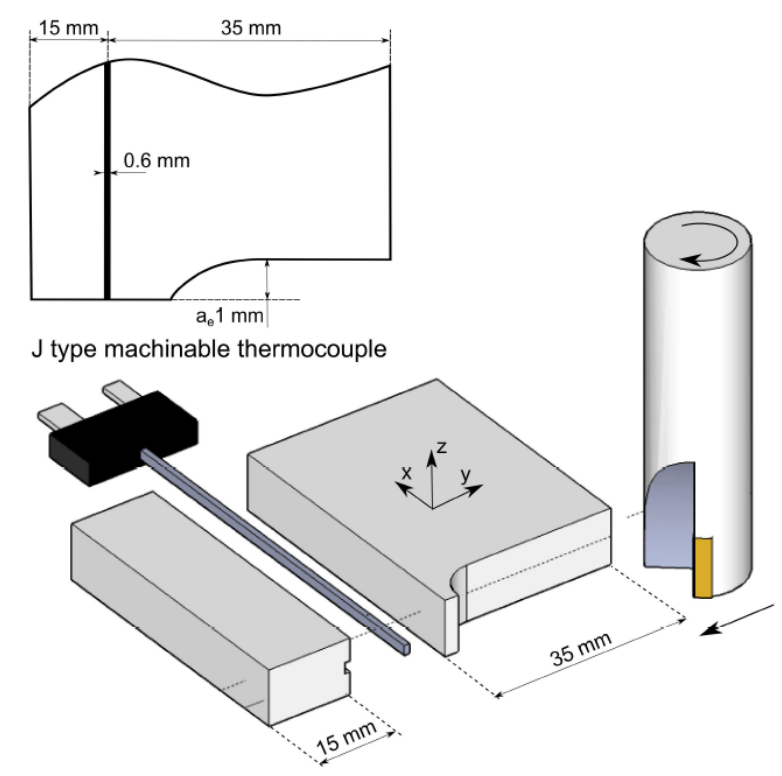

Fig.3. Schematic illustration of the surface measurement device

During the cutting test, as soon as the tool cuts off the two conductors, it causes smearing of one material upon the other and creates a first hot junction of the thermocouple $\mathrm{J}_{\text {start, }}$ as shown schematically in figure 4(a). This junction allows the measurement of the temperature at the newly generated surface and at the cutting edge. The tool progress linearly in the feed direction of the value $f_{z}$ per tooth and the operation is repeated as long as the tool cutting edges intersect the two conductors, generating a succession of junctions (intermediate hot junctions $\mathrm{J}_{\text {int }}$ ) and this until the last intersection corresponding to the final junction Jend. The number of created hot junctions depends on $d$ the tool diameter, $a_{e}$ the radial depth of cut and $f_{z}$ the feed per tooth, it is equal to $\left[a_{e}\left(d-a_{e}\right)\right] 1 / 2 / f_{z}+1$. The thermocouple measures heating and cooling cycle of the workpiece in contact with the tool for various angular position of the cutting edge, and thus for various uncut chip thickness, see figure 4(b). 


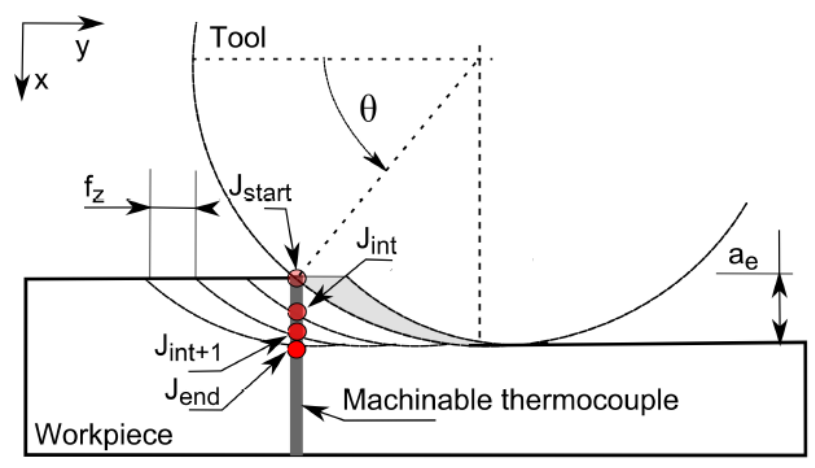

(a)

(b)

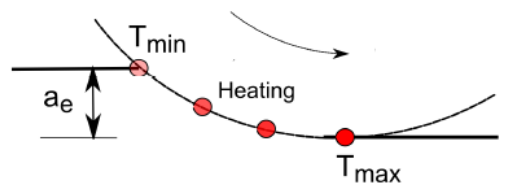

Fig.4. Principle of the machinable thermocouple: (a) the tool cuts the two conductors and creates the hot junction of the thermocouple; (b) equivalent temperature measurement locations, for the cutting edge, and during a single revolution

Between two passages of a cutting edge (or between two junctions), the temperature of the workpiece decreases of about $50^{\circ} \mathrm{C}$, figure 5 . The peak temperature (the temperature when the hot junction is created) corresponds to the temperature at the workpiece-cutting edge interface and may therefore be considered as the temperature of the cutting edge; it is the assumption which is made in the following. It is then possible to reconstruct the thermal loading of the cutting edge during a revolution from $T_{\min }$ to $T_{\max }$; that will be done on figure 9 .

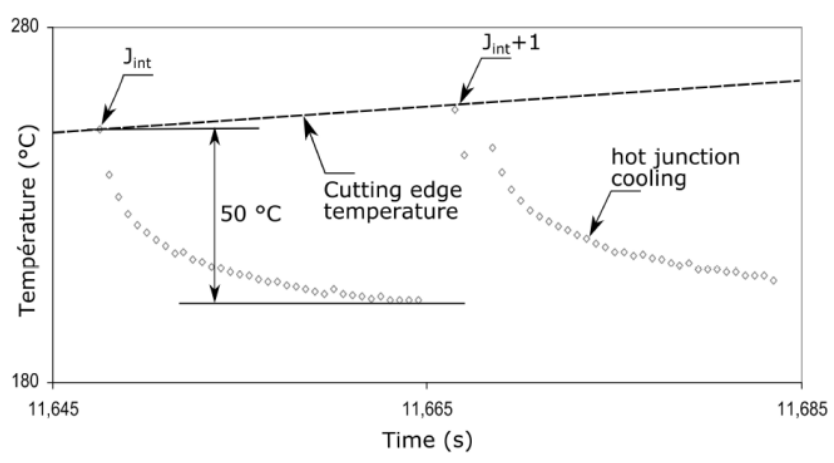

Fig.5. Temperature variation between two cutting edge actions for a cutting speed of $80 \mathrm{~m} / \mathrm{min}$. 
For the cutting speed of $80 \mathrm{~m} / \mathrm{min}$, the complete signal obtained with the machinable thermocouple is shown in Figure 6 and is compared to the signal obtained with the embedded thermocouple. When the tool is far from the two conductors, the hot junction does not exist and no signal is observed. As soon as the cutting edge of the tool cuts the two conductors of the thermocouple and creates the hot junction for the first time ( $\left.\mathrm{J}_{\text {start }}\right)$ a signal is observed with a temperature increase. Then, a succession of junctions are created ( $\mathrm{Jint}_{\text {) }}$, the measured temperature increases and decreases following the heating and cooling cycle presented Figure 5, and the peak temperature reaches its maximum $T_{\max }$ value for the last hot junction (Jend). The tool moves away from the measurement zone and the thermocouple measures the cooling of the workpiece.

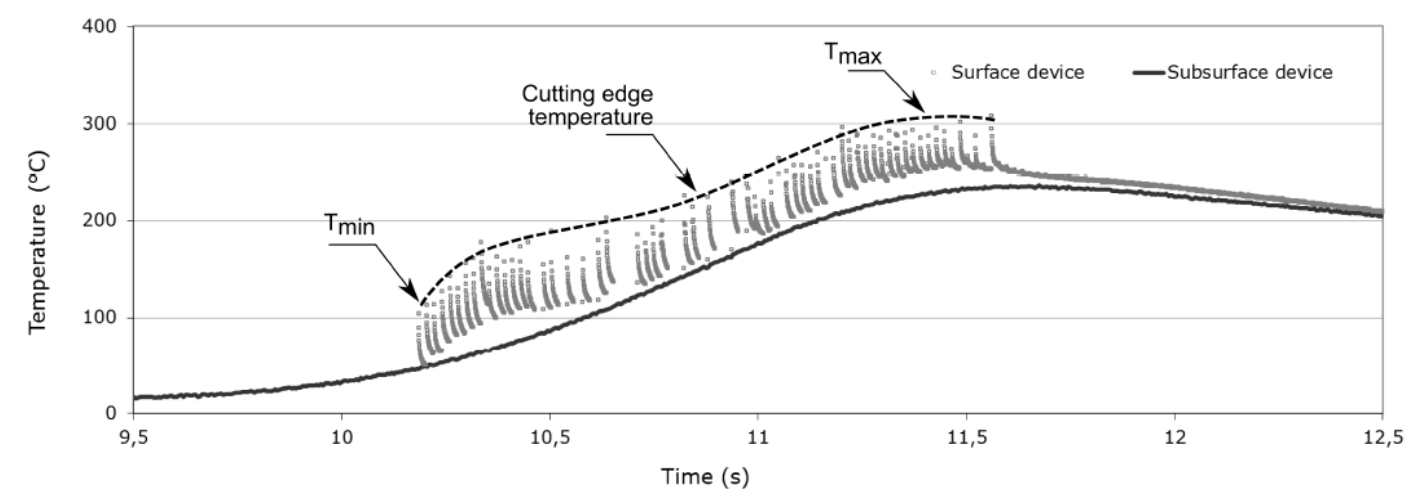

Fig.6. Comparison of surface and subsurface temperature for a cutting speed of $80 \mathrm{~m} / \mathrm{min}$.

For the two signals, the evolution of the temperature is globally the same; however, the measured temperatures values are different. Temperature in subsurface (device 1) is below the surface temperature (device 2), with a difference of about $75{ }^{\circ} \mathrm{C}$ for cutting speed of $80 \mathrm{~m} / \mathrm{min}$.

\section{EXPERIMENTAL RESULTS AND DISCUSSION.}

\subsection{Workpiece temperature and temperature gradient}

The results obtained with the two devices described previously are presented in Figure 7. In order to do not overload the figure, only the signals relating to three cutting speed values are shown. The temperature in subsurface, Figure 7(a), is first discussed. For each obtained signal, the maximum temperature attained corresponds to the passage of the tool just in front 
of the thermocouple. For the lower cutting speed of $40 \mathrm{~m} / \mathrm{min}$, this maximum temperature is about $190{ }^{\circ} \mathrm{C}$. The increase in cutting speed results, first, in an increase of this maximum. However, the maximum temperature measured by the thermocouple in subsurface seems to attain an extremum of $250^{\circ} \mathrm{C}$ for $80 \mathrm{~m} / \mathrm{min}$; and it decreases slightly for the higher values of cutting speed to reach $230^{\circ} \mathrm{C}$ for $320 \mathrm{~m} / \mathrm{min}$. In the same way, an increase of cutting speed results in an increase in the slope of the rise in temperature before the maximum. A low cutting speed of $40 \mathrm{~m} / \mathrm{min}$ induces a gentle slope, in comparison with a cutting speed of 320 $\mathrm{m} / \mathrm{min}$. At low cutting speeds and thus at low feed rates, the generated heat diffuses longer into the workpiece and as it will be shown in the following the subsurface temperature is very close to the one at machined surface. At higher cutting speed and feed rate, the thermal load is more intense, but during a shorter time; only the surface is affected by temperature and the subsurface temperature value is very similar and even lower.

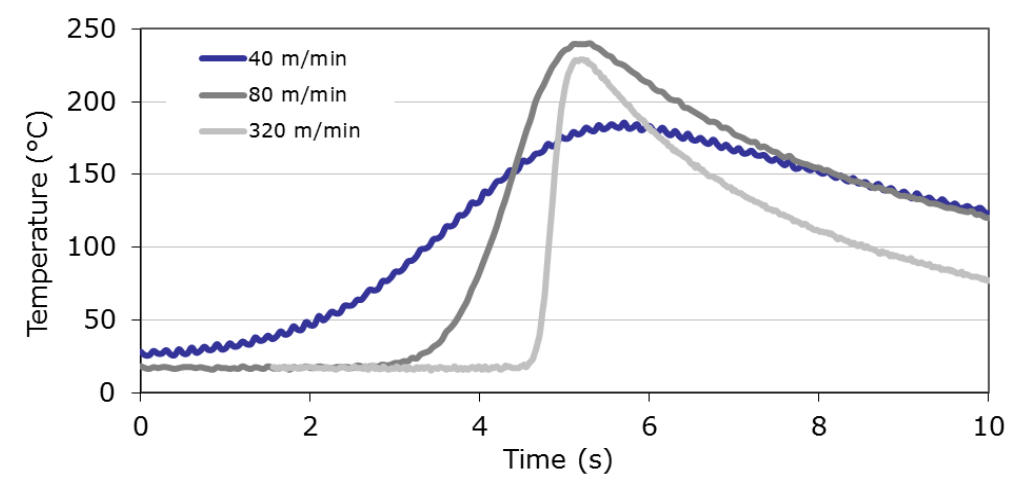

(a)

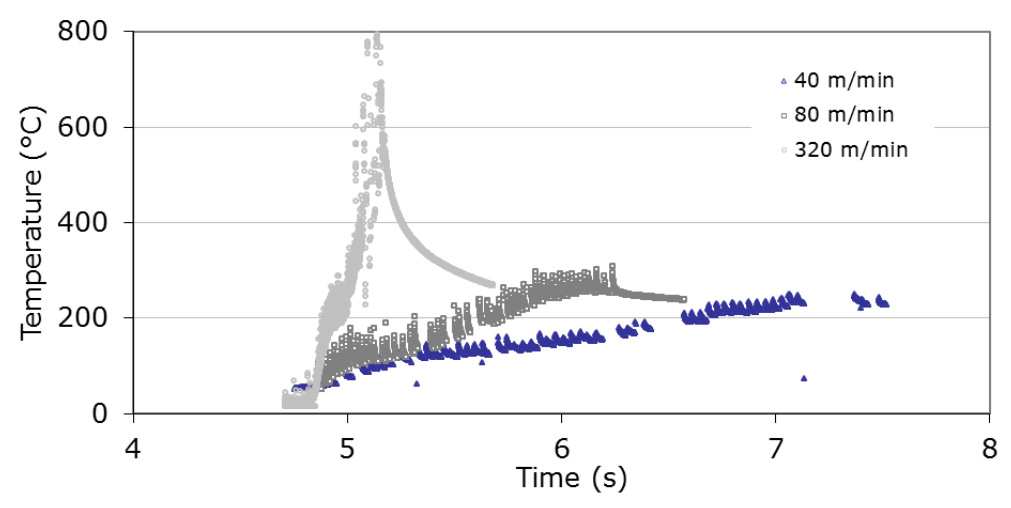

(b)

Fig.7. Temperature signals obtained by (a) the subsurface measurement device and (b) the machinable thermocouple.

These comments are confirmed by temperature measurements acquired by the machinable thermocouple, Fig. 8(b); they correspond to the machined surface temperature. It can be 
observed that, for the same cutting speed values, the maximum temperature at machined surface is much higher that the one measured in subsurface. Moreover, contrary to what was detected in subsurface, this maximum temperature increases with increasing cutting speed values. For the lower cutting speeds of 40 and $80 \mathrm{~m} / \mathrm{min}, T_{\max }$ attains respectively 250 and $31{ }^{\circ} \mathrm{C}$; and with the cutting speed of $320 \mathrm{~m} / \mathrm{min}$, the maximum temperature greatly increases and reaches $790^{\circ} \mathrm{C}$.

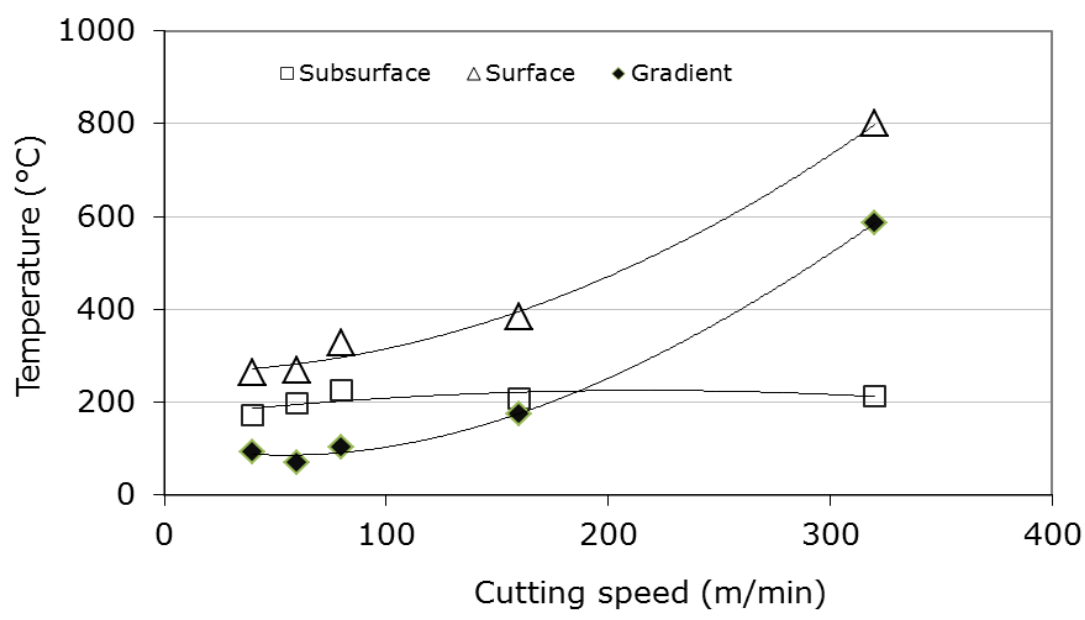

Fig. 8 Evolution of the maximum temperatures with cutting speed.

The values of the maximum temperature of the surface and of the subsurface are reported in Fig. 8, bringing out the evolution of the temperature gradient with the cutting speed. For the low cutting speeds of $40 \mathrm{~m} / \mathrm{min}$, the temperature gradient is approximately equal to $100{ }^{\circ} \mathrm{C}$. $\mathrm{A}$ minimum is observed for a cutting speed of about $60 \mathrm{~m} / \mathrm{min}$; and then for higher cutting speed values, the maximum temperature of the machined surface increases. The temperature gradient becomes very important; it attains about $600{ }^{\circ} \mathrm{C}$ in $0.5 \mathrm{~mm}$ for the cutting speed of $320 \mathrm{~m} / \mathrm{min}$. These observations confirm the low heat diffusion in the workpiece at high cutting speeds. The low thermal conductivity of Inconel 718 is responsible of this high temperature gradient between surface and subsurface.

It is well known that high surface temperatures and high temperature gradients may induce surface integrity alteration like microstructure changes, phase transformation, plastic deformation, high tensile residual stresses. A white layer was observed by Bushlya et al. when turning Inconel 718 (Bushlya et al., 2011); in the same way, phase transformation was 
mentioned by Liao et al. (2008) when milling Inconel 718. High tensile residual stresses were measured by Devillez et al. (2001) when dry turning Inconel 718 .

\subsection{Cutting edge temperature}

As explained previously, the information obtained with the machinable thermocouple are used to reconstruct the temperature evolution of the cutting edge during the formation of a single chip, see Fig. 4(b). It is supposed that the peaks temperatures, Fig. 5 and Fig. 6, correspond to the temperature at the workpiece-cutting edge interface and may therefore be considered as the temperature of the cutting edge. These peaks temperatures were measured with the machinable thermocouple for various uncut chip thickness, Fig. 4(b), from entry to exit of the cutting edge in the workpiece (from higher to zero uncut chip thickness values in down milling). Therefore, from the time dependent signal Fig. 7(b), it is possible to build the tool rotation angle dependent signal Fig. 9; and thus to obtain the heating of the cutting edge during a single revolution of the tool. The cooling of the cutting edge was not determined with the machinable thermocouple; Ueda et al. (2001) measured the tool temperature with a two-color pyrometer at various tool rotation angles and they supposed a linear decreasing of tool temperature during the cooling; Sato et al. (2011) defined it as an exponential decreasing.

As an example, Fig. 9 presents the heating process of a cutting edge for the cutting speed of $80 \mathrm{~m} / \mathrm{min}$. At the beginning of the chip formation, the cutting edge is at the temperature $T_{\min }$ of about $100{ }^{\circ} \mathrm{C}$; the cutting edge is then heated by the cutting process until a maximum temperature $\mathrm{T}_{\max }$ of about $310^{\circ} \mathrm{C}$. The temperature variation $\Delta \mathrm{T}=\mathrm{T}_{\max }-\mathrm{T}_{\min }$ of the cutting edge was thus estimated to $210^{\circ} \mathrm{C}$ for a rotation angle of $29^{\circ}$ realized in less than $5 \mathrm{~ms}$; and the cutting insert suffered this thermal shock 26 times per second for this value of cutting speed and for a diameter of tool $16 \mathrm{~mm}$. This information is important when interest is focused on tool wear.

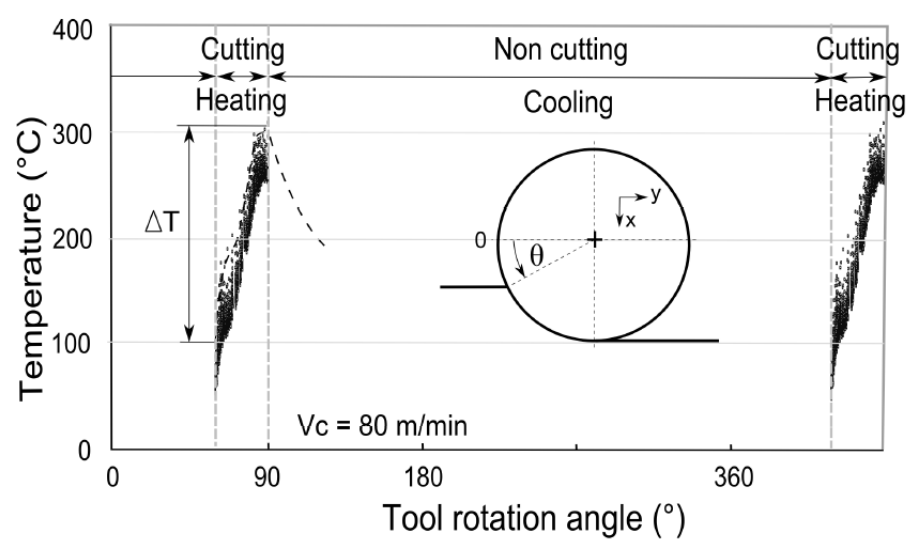


Fig.9. evolution of the cutting edge temperature during one tool revolution.

The same treatment was done for all the obtained signals and for all the tested cutting speed values. It was therefore possible to determine the evolution of the temperatures $T_{\text {min }}$ and $T_{\max }$, and to calculate the thermal shock $\Delta \mathrm{T}$, for each cutting speed value, Fig. 10. The thermal shock $\Delta \mathrm{T}$ varies from $150^{\circ} \mathrm{C}$ (at 40 and $60 \mathrm{~m} / \mathrm{min}$ ) to $600{ }^{\circ} \mathrm{C}$ (at $320 \mathrm{~m} / \mathrm{min}$ ). Ueda et al. (2001) measured a lower thermal shock of $120^{\circ} \mathrm{C}$ when milling AISI 1045 steel at a cutting speed of $471.2 \mathrm{~m} / \mathrm{min}$; and Sato et al. (2011) estimated a thermal shock of about $300^{\circ} \mathrm{C}$ on tool cutting face when milling titanium at a cutting speed of $214 \mathrm{~m} / \mathrm{min}$. Inconel 718 is a high strength material whose mechanical properties are superior to those of these materials, and the values obtained in the present study, for the thermal shock, are quite related to those found previously.

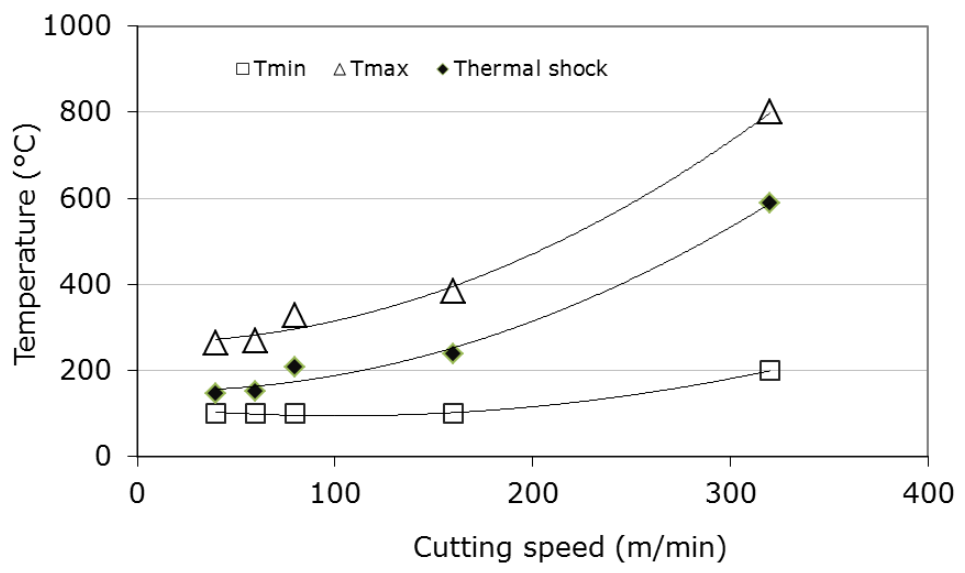

Fig.10. Evolution of $T_{\min }, T_{\max }$ and thermal shock $\Delta \mathrm{T}$ with cutting speed

The increasing of cutting edge temperature with cutting speed was confirmed by the examination of the inserts after peripheral milling tests. Fig. 11 presents the inserts used at cutting speed of $80 \mathrm{~m} / \mathrm{min}$ and $320 \mathrm{~m} / \mathrm{min}$. A built-up edge can be observed for the higher cutting speed; the apparition of this built-up edge is directly associated to the increase of cutting edge temperature. 


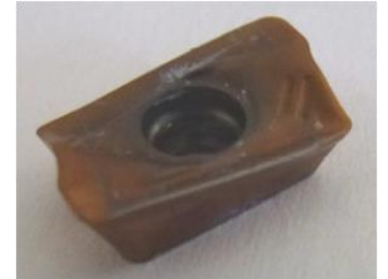

(a)

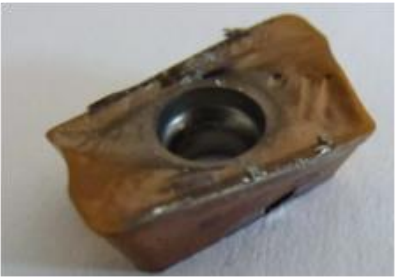

(b)

Fig.11. R390 (1030) inserts after milling test with a cutting speed of (a) $80 \mathrm{~m} / \mathrm{min}$ and (b) 320 $\mathrm{m} / \mathrm{min}$

\section{CONCLUSIONS.}

The aim of this experimental work was to evaluate the cutting temperature and the temperature gradient in the workpiece during peripheral milling Inconel 718 . With this objective, two experimental set ups were developed. The temperatures on the machined surface and in the subsurface were evaluated. The determination of the temperature at the tool-workpiece interface was made possible by the development of an original thermocouple; this one was a machinable thermocouple. In addition, the determination of the heating of the cutting edge during a tool revolution was reconstituted from measurements of this thermocouple. The influence of the cutting speed on the temperature levels and on the temperature gradients was investigated. The main results are:

1. When machining a low conductivity material such as Inconel 718 , the location of the temperature measurement means is very important on the results. A thermocouple placed at $0.5 \mathrm{~mm}$ from the machined surface does not observe a temperature rise with increasing cutting speed. This temperature rise is detected in surface by the machinable thermocouple specifically designed.

2. A large temperature gradient was observed from the surface to the subsurface, especially for the higher cutting speeds. For a cutting speed of $320 \mathrm{~m} / \mathrm{min}$, the temperature gradient reaches $600{ }^{\circ} \mathrm{C}$ for a layer of $0.5 \mathrm{~mm}$ thickness. The low thermal diffusivity of Inconel 718 contributes to this high gradient.

3. A minimum value for the temperature gradient was noticed for the cutting speed of 60 $\mathrm{m} / \mathrm{min}$. This cutting speed seems to be the optimal one when dry machining Inconel 718 with a coated carbide tool. 
4. The cutting edge of the tool insert undergoes a thermal shock at each revolution. Its intensity and frequency depend on the cutting conditions. The temperature variation reaches $600{ }^{\circ} \mathrm{C}$ for a cutting speed of $320 \mathrm{~m} / \mathrm{min}$ and is caused about hundred times per second.

For dry machining of difficult to cut materials, the cutting temperature is an important parameter for the optimization of cutting conditions. However, this one must be measured as close as possible to the cutting area; in addition, it is also essential to know the temperature gradients. A moderate level of cutting edge temperature and a low thermal shock reduce the tool wear phenomena; and, a low temperature gradient in the sub machined layer reduces the risk of high tensile residual stresses.

\section{REFERENCES.}

Bushlya, V., Zhou, J.M., Lenrick, F., Avdovic, P., Ståhl, J-E., 2011. Characterization of White Layer Generated when Turning Aged Inconel 718. $1^{\text {st }}$ CIRP Conf. on Surface Integrity (CSI), Procedia Engineering 19, 60-66

Coelho, R.T., Silva, L.R., Braghini, A., Jr., Bezerra, A.A., 2004. Some effects of cutting edge preparation and geometric modifications when turning Inconel $718^{\mathrm{TM}}$ at high cutting speeds. J. Mat. Process. Tech. 148 147-153

Courbon, C., Kramar, D., Krajnik, P., Pusavec, F., Rech, J., Kopac, J., 2009. Investigation of machining performance in high-pressure jet assisted turning of Inconel 718: An experimental study. Int. J. Mach. Tools \& Manu. 49, 1114-1125

Devillez, A., Le Coz, G., Dominiak, S., Dudzinski, D., 2011. Dry machining of Inconel 718, workpiece surface integrity. J. Mat. Process. Tech. 211, 1590-1598

El-Wardany, T.I., Mohammed, E., Elbestawi, M.A., 1996. Cutting temperature of ceramic tools in high speed machining of difficult-to-cut materials. Int. J. Mach. Tools \& Manu 36/5, 611-634 
Kitagawa, T., Kubo, A., Maekawa, K., 1997. Temperature and wear of cutting tools in highspeed machining of Incone1718 and Ti-6A1-6V-2Sn. Wear 202, 142 - 148

Le Coz, G., Marinescu, M., Devillez, A., Dudzinski, D., Velnom, L., 2012. Measuring temperature of rotating cutting tools: Application to MQL drilling and dry milling of aerospace alloys. App. Thermal Eng. 36, 434-441

Lezanski, P., Shaw, M.C., 1990. Tool face temperatures in high speed milling, Transactions of ASME. J. Eng. Industry 112, 132-135

Liao, Y.S., Lin, H.M., Wang, J.H., 2008. Behaviors of end milling Inconel 718 superalloy by cemented carbide tools, J. Mat. Process. Tech. 201, 460-465

Lin, J., 2995. Inverse estimation of the tool work interface temperature in end milling. Int. J. Mach. Tools \& Manu. 35, 751-760

Ming, C., Fanghong, S., Haili, W., Renwei, Y., Zhenghong, Q., Shuquiao, Z., 2003. Experimental research on the dynamic characteristics of the cutting temperature in the process of high speed milling. J. Mat. Process. Tech. 138, 468-471

Narutaki, N., Yamane, Y., Hayashi, K., Kitigawa, T., 1993. High Speed Machining of Inconel 718 with Ceramic Tools. Annals of the CIRP 42/1

Ng, E.-G., Lee, D. W., Sharman, A. R. C., Dewes, R. C., Aspinwall, D. K., 2000. High Speed Ball Nose End Milling of Inconel 718. Annals of the CIRP 49/1

Pittalà, G.M., Monno, M., 2011. A new approach to the prediction of temperature of the workpiece of face milling operations of Ti-6Al-4V. App. Thermal Eng. 31, 173-180

Sato, M., Ramura, N., Tanaka, H., 2011. Temperature variation in the cutting tool in end milling. J. Manu. Sc. Eng. 133, 1-7

Ueda, T., Hosokawa, A., Oda, K., Yamada, K., 2001. Temperature on flank face of cutting tool in high speed milling. Annals of the CIRP 50/1, 37-40 